\title{
Comunicação/Communication
}

\section{Leishmania (Leishmania) infantum chagasi em canídeos silvestres mantidos em cativeiro, no Estado de Mato Grosso}

\author{
Leishmania (Leishmania) infantum chagasi in wild canids kept in captivity in the State of Mato \\ Grosso
}

\author{
Nely Pinheiro Souza ${ }^{1}$, Arleana do Bom Parto Ferreira de Almeida ${ }^{2}$, Tatiana Pádua Tavares de Freitas ${ }^{1}$, \\ Regina Celia Rodrigues da Paz ${ }^{1}$, Valéria Dutra ${ }^{1}$, Luciano Nakazato ${ }^{1}$ e Valéria Régia Franco Sousa ${ }^{1}$
}

\begin{abstract}
RESUMO
Introdução: Leishmaniose visceral é uma zoonose que acomete diversos mamíferos tendo os canídeos domésticos como principais reservatórios em ambiente urbano. A presente nota descreve a infecção de canídeos silvestres por Leishmania (Leishmania) infantum chagasi mantidos em cativeiro no Estado de Mato Grosso, Brasil. Métodos: De seis raposas (Cerdocyon thous) e um cachorro vinagre (Spheotos venaticus), foram coletadas amostras de pele, medula óssea e linfonodo para detecção e caracterização de Leishmania sp pela técnica de PCR-RFLP. Resultados: Todos as animais pesquisados apresentaram-se positivos para Leishmania (L.) infantum chagasi. Conclusões: Destaca-se a importância de monitoramento adequado dos mesmos, além do maior controle desta enfermidade já que estes animais estão em ambientes de recreação pública.
\end{abstract}

Palavras-chaves: Leishmania (Leishmania) infantum chagasi. Mamíferos silvestres. Mato Grosso.

\begin{abstract}
Introduction: Visceral leishmaniasis is a zoonosis that affects many mammals, and domestic canids are the main reservoirs in urban environments. This note describes infection by Leishmania (Leishmania) infantum chagasi among wild canids kept in captivity in the State of Mato Grosso, Brazil. Methods: Skin, bone marrow and lymph node samples were collected from six crab-eating foxes (Cerdocyon thous) and one bush dog (Spheotos venaticus), in order to detect and characterize Leishmania using the PCR-RFLP technique. Results: All the animals studied were positive for Leishmania (L.) infantum chagasi. Conclusions: This study highlights the importance of adequate monitoring of these animals, as well as greater control of this disease, given that these animals are in a public recreation environment.
\end{abstract}

Key-words: Leishmania (Leishmania) infantum chagasi. Wild mammals. Mato Grosso.

\footnotetext{
1. Departamento de Clínica Médica Veterinária, Faculdade de Agronomia e Medicina Veterinária, Universidade Federal de Mato Grosso. Cuiabá, MT. 2. Doutoranda em Pesquisa Clínica em Doenças Infecciosas, Instituto de Pesquisa Clínica Evandro Chagas, Fundação Oswaldo Cruz. Rio de Janeiro, RJ.

Endereço para correspondência: Prof a Valéria Régia Franco Sousa. Dept ${ }^{\circ}$ de Clínica Médica Veterinária/FAMEV/UFMT. Av. Fernando Correa s/n. Boa Esperança, 78060-900 Cuiabá, MT.

Telefax: 5565 3615-8664

e-mail: regia@ufmt.br

Recebido para publicação em 27/10/2009

Aceito em 18/01/2010
}

Leishmaniose visceral é uma zoonose em crescente expansão no Brasil, causada pela Leishmania (Leishmania) infantum chagasi, tendo o cão como principal reservatório em ambiente urbano ${ }^{1}$, mantendo o ciclo de transmissão nesses locais. Esta enfermidade é transmitida pelo flebotomíneo Lutzomyia longipalpis e L. cruzi².

Diversos mamíferos podem se infectar por Leishmania $\mathrm{sp}^{3}$; entretanto, não são usualmente responsáveis pela transmissão ao homem ${ }^{4}$. No Brasil, dos canídeos silvestres, somente a raposa (Cerdocyon thous) é considerada reservatório natural da leishmaniose visceral $^{5}$. Todavia, diversas espécies já foram relatadas com infecção, como lobo guará (Chysocyon brachyurus $)^{6}$, raposa-do-campo (Lycalopex vetulus) e cachorro-vinagre (Spheotos venaticus) ${ }^{7}$, além de outros mamíferos como o marsupial Didelphis albiventris e D. marsupialis ${ }^{8}$.

Nesta comunicação, descreve-se a infecção de canídeos silvestres, Cerdocyon thous e Spheotos venaticus por Leishmania (L.) i. chagasi mantidos em zoológico da Universidade Federal de Mato Grosso, Estado de Mato Grosso, Brasil.

$\mathrm{Na}$ pesquisa, avaliou-se a ocorrência de leishmaniose em seis raposas, sendo dois machos e quatro fêmeas, adultos e um cachorro vinagre, fêmea, adulta, oriundos do zoológico da Universidade Federal de Mato Grosso, sendo o estudo aprovado pelo sistema SISBIO/IBAMA no. 11064-1. Dos animais coletados, uma raposa fêmea apresentava alterações clínicas compatíveis com leishmaniose visceral como dermatite furfurácea, uveíte, onicogrifose, emagrecimento, hepatoesplenomegalia e o cachorro vinagre apresentava alopecia nos membros, região da face e periocular, onicogrifose e conjuntivite.

Para a análise da infecção por Leishmania sp, procedeu-se a coleta de pele, aspirado de medula óssea e linfonodo poplíteo. Após contenção física com puçá e imobilização química, utilizando-se o fármaco tiletamina-zolazepan na dose de $6 \mathrm{mg} / \mathrm{kg}$, os fragmentos cutâneos foram obtidos da orelha através de biópsia incisional, após prévia assepsia local. As amostras de medula óssea das raposas foram obtidas do processo xifóide do esterno. Do cachorro-vinagre, a amostra foi obtida da crista ilíaca. Os aspirados ganglionares foram obtidos dos linfonodos poplíteos. As amostras coletadas foram acondicionadas em microtubos sob refrigeração e encaminhadas ao Laboratório de Biologia Molecular do HOVET-UFMT, sendo mantidas a $-20^{\circ} \mathrm{C}$, até o processamento. 
Para extração de DNA, as amostras foram processadas de acordo com Andrade e cols ${ }^{9}$. Sucintamente, as amostras foram colocadas em tampão de lise contendo $10 \mathrm{mM}$ Tris- $\mathrm{HCl}, \mathrm{pH} 8.0 ; 25 \mathrm{mM}$ EDTA; $100 \mathrm{mM} \mathrm{NaCl} ; 0.5 \%$ SDS e $100 \mu \mathrm{g} / \mathrm{ml}$ de proteinase $\mathrm{K}$, e incubadas a $56^{\circ} \mathrm{C}$, até completa lise celular. Os aspirados de medula óssea, linfonodo e fragmento de pele foram incubados por cerca de 12-18 horas. A seguir, utilizou-se o método fenol-clorofórmio e precipitação por isopropanol. Após lavagem com etanol $70 \%$, por 10 minutos, a $10,000 \mathrm{~g}$, o DNA foi ressuspendido em água ultrapura. A qualidade e integridade do DNA foram observadas em gel de agarose.

A reação em cadeia pela polimerase foi realizada utilizando os primers 150 (sense) 5'-GGG(G/T)AGGGGCGTTCT(C/G)CGAA3' e 152 (antissense) 5' (C/G) (C/G)(C/G)(A/T)CTAT(A/T) TTACACCAACCCC-3' que amplificam um fragmento de $120 \mathrm{pb}$ de uma região conservada do minicírculo kDNA de todas as espécies de Leishmania ${ }^{10}$. O produto de amplificação foi fracionado por eletroforese em gel de agarose $2 \%$, corado com brometo de etídeo e analisado em transluminador (UV-300nm).

Polymerase chain reaction-restriction fragment length polymorphism (PCR-RFLP) mkDNA foi realizado de acordo com Andrade e cols 9 . Cinco microlitros do produto da amplificação foram digeridos por $1 \mathrm{U}$ da enzima HaeIII, durante 3 horas a $37^{\circ} \mathrm{C}$. Fragmentos de restrição foram separados em gel de poliacrilamida a $10 \%$ corado com brometo de etídeo. Os fragmentos obtidos foram comparados com as cepas padrão de L. (L.) i. chagasi (MHOM/BR/74/PP75) e Leishmania (Viannia) braziliensis (MHOM/BR/75/M2903), provenientes do Instituto Oswaldo Cruz/FIOCRUZ, Rio de Janeiro.

As amostras de medula óssea, linfonodo e fragmentos cutâneos das seis raposas e do cachorro-vinagre foram positivas para a presença de DNA e Leishmania sp, sendo caracterizadas como sendo L. (L.) i. chagasi pela técnica de PCR-RFLP (Figura 1).

Com o processo de urbanização da leishmaniose visceral, o cão detém maior importância como reservatório do parasita. No entanto, as raposas (Cerdocyon thous) atuam como reservatório primário do agente no ciclo enzoótico rural ${ }^{5}$. Como nos canídeos domésticos, esses animais frequentemente apresentam-se assintomáticos, enquadrando-o mais perfeitamente nas características esperadas para um reservatório ${ }^{11}$. Neste estudo, apenas um exemplar da espécie Cerdocyon thous apresentou-se sintomático ${ }^{12} \mathrm{com}_{\text {dermatite }}$ furfurácea, emagrecimento progressivo, onicogrifose, uveíte e hepato-esplenomegalia. Segundo Molina e cols ${ }^{13}$, a importância dos canídeos no ciclo de transmissão da leishmaniose advém da alta carga parasitária apresentada na pele, sendo importante fonte de infecção para o vetor. Apesar da não quantificação parasitária, na pele dos animais, todos os fragmentos cutâneos, obtidos de pele íntegra, apresentaram-se com DNA de $L$. ( $L$. $)$ i. chagasi realçando a importância deles na cadeia epidemiológica.

De acordo com Courtenay e $\operatorname{cols}^{14}$, a infectividade das raposas ao vetor é menor quando comparado com os canídeos domésticos. Entretanto, a circulação descontrolada desses animais, entre zoológicos, promove a disseminação e introdução do agente para áreas não endêmicas ${ }^{7}$. A procedência das raposas analisadas neste estudo é desconhecida, o que dificultou estabelecer a origem da infecção nos mesmos. Porém, o relato da estadia dos animais há mais de três anos no zoológico, somando-se ao ambiente do confinamento propício para manutenção do vetor ${ }^{4}$ e a região ser endêmica para a doença, com ocorrência de casos caninos domésticos, em áreas ao redor do zoológico ${ }^{15}$, cogita a hipótese de infecção no referido ambiente.

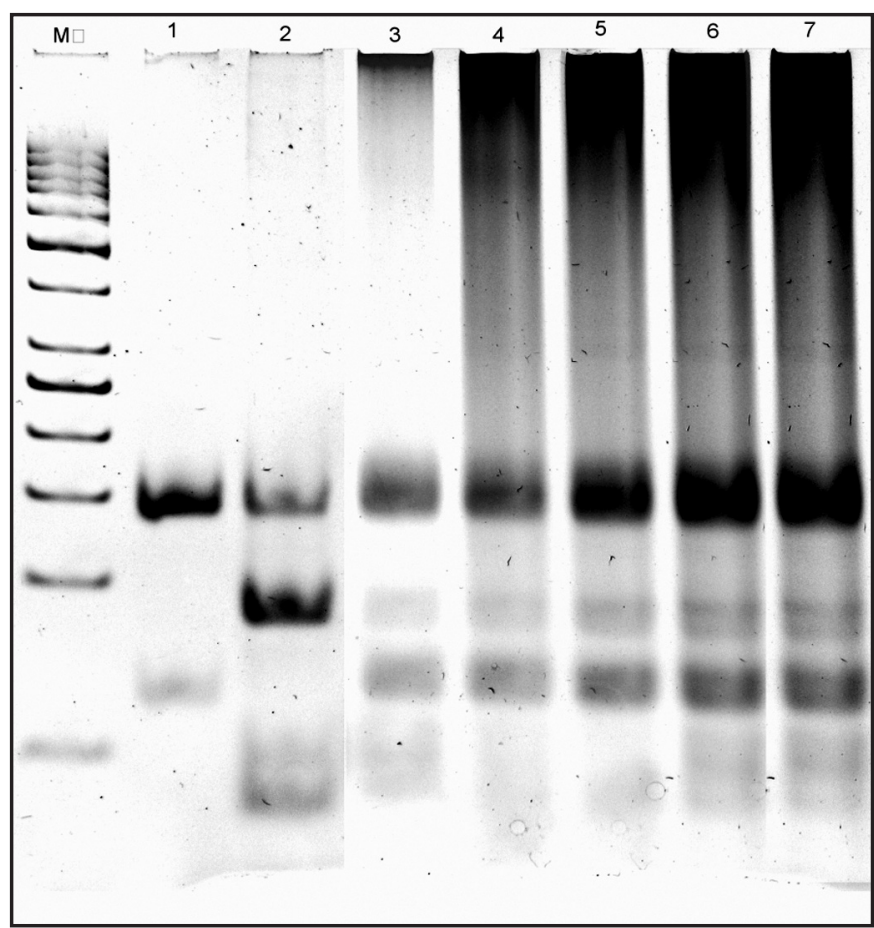

FIGURA 1 - RFLP (Restriction fragment length polymorphisms) de 120pb da amplificação de kDNA de Leishmania obtido com enzima de restrição Hae III e analisado em gel de poliacrilamida a $10 \%$ corado com brometo de etídeo. Linhas: M. marcador molecular de 50pb; 1. L. (L.) infantum chagasi (MHOM/BR/74/ PP75); 2. L. (V.) braziliensis (MHOM/BR/75/M2903); 3 a 7 - amplificação de DNA de amostra de fragmentos de pele de quatro raposas e um cachorro-vinagre, respectivamente.

Recentemente, diagnosticou-se infecção por L. (L.) i. chagasi em cachorro-vinagre de zoológico do Rio de Janeiro, proveniente do Estado de Mato Grosso 7 . Diferente do cachorro-vinagre, relatado no trabalho supracitado, o animal estudado apresentava sinais clínicos compatíveis com a doença como onicogrifose, alopecia difusa, emagrecimento progressivo e hepato-esplenomegalia, sendo este proveniente de Barão de Melgaço, município situado no Pantanal Matogrossense, onde habitava em ambiente peridomiciliar juntamente com cães, sendo encaminhado há cerca de dois meses para o zoológico da UFMT.

A caracterização da espécie, nas amostras obtidas, como sendo L. (L.) i. chagasi, confirmou o Cerdocyon thous como reservatório primário da leishmaniose visceral no Brasil ${ }^{5}$. A detecção da infecção de cachorros-vinagre por $L$. (L.) chagasi é recente ${ }^{4,7}$, não se sabendo ainda a importância dos mesmos no ciclo de transmissão.

O encontro de canídeos, confinados em zoológicos do Brasil, com infecção por $L$. ( $L$. ) chagasi, denota a relevância de novos estudos com estes animais, alguns deles ameaçados de extinção como o cachorrovinagre, visa conhecer o papel dos mesmos na epidemiologia dessa zoonose e promove o monitoramento adequado dos mesmos, além do maior controle desta enfermidade, já que estes animais estão em ambientes de recreação pública.

\section{CONFLITO DE INTERESSE}

Os autores declaram não haver nenhum tipo de conflito de interesse no desenvolvimento do estudo. 
FAPEMAT, CNPq-DECIT.

\section{REFERÊNCIAS}

1. Palatnik-De-Sousa CB, Santos WR, França-Silva JC, Costa RT, Reis AB, Palatnik $\mathrm{M}$, et al. Impact of canine control on the epidemiology of canine and human visceral leishmaniasis in Brazil. Am J Trop Med Hyg 2001; 65:510-517.

2. Santos SO, Arias J, Ribeiro AA, Hoffmann MP, Freitas RA, Malacco MAF. Incrimination of Lutzomyia cruzi as a vector of American Visceral Leishmaniasis. Med Vet Entomol 1998; 12:315-317.

3. Dantas-Torres F. The role of dogs as reservoirs of Leishmania parasites with emphasis on Leishmania (Leishmania) infantum and Leishmania (Viannia) braziliensis. Vet Parasitol 2007; 149:139-146.

4. Luppi MM, Malta MCC, Silva TMA, Silva FL, Motta ROC, Miranda I, et al. Visceral leishmaniasis in captive wild canids in Brazil. Vet Parasitol 2008; 155:146-151.

5. Sherlock IA. Ecological interactions of visceral leishmaniasis in the state of Bahia, Brazil. Mem Inst Oswaldo Cruz 1996; 91:671-683.

6. Curi NHA, Miranda I, Talamoni SA. Serologic evidence of leishmania infection in free-ranging wild and domestic canids around a Brazilian national park. Mem Inst Oswaldo Cruz 2006; 101:99-101.

7. Figueiredo FB, Gremião ID, Pereira SA, Fedulo LP, Menezes RC, Balthazar DA, et al. First report of natural infection of a bush dog (Speothos venaticus) with Leishmania (Leishmania) chagasi in Brazil. Trans R Soc Trop Med Hyg 2008; 102:200-201.

8. Travi BL, Osório Y, Guarín N, Cadena H. Leishmania (Leishmania) chagasi: Clinical and Parasitological Observations in Experimentally Infected Didelphis marsupialis, Reservoir of New World Visceral Leishmaniasis. Exp Parasitol 1998; 88:73-75

9. Andrade HM, Reis AB, Santos SL, Volpini AC, Marques MJ, Romanha AJ. Use of PCR-RFLP to identify Leishmania species in naturally-infected dogs. Vet Parasitol 2006; 140:231-238.

10. Degrave W, Fernandes O, Campbell D, Bozza M, Lopes UG. Use of molecular probes and PCR for detection and typing of Leishmania - a mini-review. Mem Inst Oswaldo Cruz 1994; 89:463-469.

11. Ashford RW. Leishmaniasis reservoirs and their significance in control. Clin Dermatol 1996; 14:523-532.

12. Mancianti F, Gramiccia M, Gradoni L, Pieri S. Studies on canine leishmaniasis control. I. Evolution of infection of different clinical forms of canine leishmaniasis following antimonial treatment. Trans R Soc Trop Med Hyg 1988; 82:566 567.

13. Molina R, Amela C, Nieto J, San-Andrés M, González F, Castillo JA, et al. Infectivity of dogs naturally infected with Leishmania infantum to colonizad Phlebotomus perniciosus. Trans R Soc Trop Med Hyg 1994; 88: 491-493.

14. Courtenay O, Quinnell RJ, Garcez LM, Dye C. Low infectiousness of a wildlife host of Leishmania infantum: the crabeating fox is not important for transmission. Parasitol 2002; 125: 407-414.

15. Almeida ABPF, Faria RP, Pimentel MFA, Dahroug MAA, Turbino NCMR, Sousa VRF. Inquérito soroepidemiológico de leishmaniose canina em áreas endêmicas de Cuiabá, Estado de Mato Grosso. Rev Soc Bras Med Trop 2009; 42:156-159. 